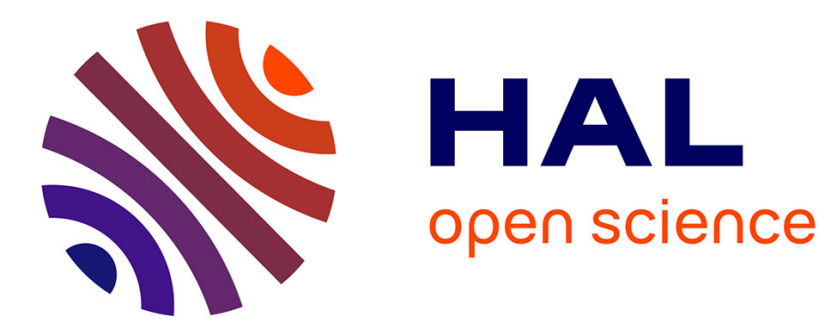

\title{
Suidae from Kanapoi
}

Denis Geraads, René Bobe

\section{- To cite this version:}

Denis Geraads, René Bobe. Suidae from Kanapoi. Journal of Human Evolution, 2020, 140, pp.102337. 10.1016/j.jhevol.2017.05.004 . hal-02884074

\section{HAL Id: hal-02884074 https://hal.sorbonne-universite.fr/hal-02884074}

Submitted on 29 Jun 2020

HAL is a multi-disciplinary open access archive for the deposit and dissemination of scientific research documents, whether they are published or not. The documents may come from teaching and research institutions in France or abroad, or from public or private research centers.
L'archive ouverte pluridisciplinaire HAL, est destinée au dépôt et à la diffusion de documents scientifiques de niveau recherche, publiés ou non, émanant des établissements d'enseignement et de recherche français ou étrangers, des laboratoires publics ou privés. 
GERAADS Denis \& BOBE René

Suidae from Kanapoi.

Journal of Human Evolution. 2020. http://dx.doi.org/10.1016/j.jhevol.2017.05.004

Denis Geraads ${ }^{a, b}$ *

${ }^{a}$ Sorbonne Universités - CR2P-MNHN, CNRS, UPMC-Paris 6 - CP 38, Muséum National d'Histoire Naturelle, 8 rue Buffon, F-75231 Paris Cedex 05, France;

${ }^{\mathrm{b}}$ Max Planck Institute for Evolutionary Anthropology, Department of Human Evolution, Deutscher Platz 6 - D-04103 Leipzig - Germany

René Bobe ${ }^{\mathrm{c}, \mathrm{d}}$

${ }^{\mathrm{c}}$ Departamento de Antropología, Universidad de Chile, Santiago, Chile

${ }^{\mathrm{d}}$ Institute of Cognitive \& Evolutionary Anthropology, University of Oxford, Oxford, UK

* corresponding author

denis.geraads@mnhn.fr 


\begin{abstract}
The whole collection of Suidae from Kanapoi is revised, in the context of the systematics and evolution of Nyanzachoerus in the Pliocene of Eastern Africa. It contains only two species, Nyanzachoerus kanamensis and Notochoerus jaegeri. The size and morphology of their premolars overlap, but not those of their m3s. No transitional form between them is known in Kenya, but some populations from Uganda and Ethiopia display intermediate characters, suggesting that No. jaegeri could be descended from a kanamensislike ancestor. However, the cranial remains of No. jaegeri from Kanapoi are insufficient to formally establish the affinities of the species. On the basis of the dentition, No. euilus could be descended from No. jaegeri. The noticeable absence of Kolpochoerus at Kanapoi (and in the whole Turkana Basin at that time) remains unexplained. The presence of a species close to Ny. tulotos at Ekora raises the question of possible occurrence of uppermost Miocene sediments there.
\end{abstract}

Keywords: Africa; Kenya; Pliocene; Kanapoi; Suidae;

\title{
1. Introduction
}

Cooke and Ewer (1972) described in detail the suid material collected by the Harvard University expeditions. They assigned the bulk of the material to two new species of Nyanzachoerus (hereafter Ny.), Ny. pattersoni and Ny. plicatus, but also attributed a few, mostly incomplete or weathered specimens to Notochoerus (hereafter No.), tentatively calling them No. cf. capensis Broom, 1925, and No. cf. euilus Hopwood, 1926. Harris et al. (2003) revised this material and additionally described the material collected in the 1990s by the National Museums of Kenya expeditions. They accepted $N y$. pattersoni as a valid species but, following Harris and White (1979), they regarded Ny. plicatus as a synonym of $\mathrm{Ny}$. jaegeri Coppens, 1971, first described from Tunisia. However, they assigned this species to Notochoerus, and also included in it the material identified as Notochoerus by Cooke and Ewer (1972). Still, they considered that a mandible represents No. cf. euilus. Last, Geraads et al. (2013) concluded that there are only two species, No. jaegeri and Ny. kanamensis. We have revised the whole collection from Kanapoi, stored in the National Museums of Kenya (KNM), including all the material collected up to 2016. It numbers more than 300 specimens, including a large number of premolars and third molars. Comparisons have mostly been conducted with the Suidae from other Kenyan sites in the KNM, and with those from some Ethiopian sites in the National Museum of Ethiopia, Addis Ababa (NME); some additional 
specimens have been examined in the Muséum National d'Histoire Naturelle, Paris (MNHN), and in the Natural History Museum, London (NHMUK). Measurements follow the methodology of Harris and White (1979), i.e. length (L) is taken at the cervix along the crown midline, and width (W) is maximum. Almost all of those used in the graphs were taken by ourselves; we checked that those published by Harris et al. (2003) differ little from ours. It should be noted, however, that we could not find some of the specimens reported by these authors, probably because their accession numbers were incorrectly noted.

\section{Systematic paleontology}

Family Suidae Gray, 1821

Subfamily Tetraconodontinae Lydekker, 1876

We follow here the tradition in placing the genera Nyanzachoerus and Notochoerus (see Supplementary Information for the use of this name) in this subfamily, which remains poorly defined by features such as the reduction of $\mathrm{P} 2 / \mathrm{p} 2$ (but this is also true of the Suinae Potamochoerus), and large size of the following premolars (Orliac et al., 2010), but this is obviously not true of Notochoerus. Van der Made (1999) added that the metacone of P4 is indistinct, but this is not true of unworn teeth. Pickford (2014) concluded that the subfamily is probably paraphyletic; clearly, the validity of this subfamily remains to be better substantiated.

Genus Nyanzachoerus Leakey, 1958

Nyanzachoerus is a large suid that has characteristic zygomatic inflations. They differ from those of Notochoerus in being quite rounded, not protruding very far, directed laterally or slightly ventro-laterally, and from those of Kolpochoerus in being restricted to the anterior part of the zygomatic arch, so that the skull abruptly narrows immediately behind them. The forehead is broad, depressed, and bordered by longitudinal swellings above the orbit, which is not shifted backwards. It has a shallow ante-orbital depression, and the supra-canine flange is moderate, showing that its snout muscles were weaker than in fossorial suids such as Potamochoerus. The sexually dimorphic canines are not very large, upper and lower last two premolars are quite large, and the third molars undergo some lengthening in evolution, but remain short. 
= Nyanzachoerus pattersoni Cooke and Ewer, 1972

Cooke and Ewer (1972), followed by Harris et al. (2003) described the most common suid species at Kanapoi as Ny. pattersoni but, as discussed by Geraads et al. (2013), there is no reason to distinguish this form from $N y$. kanamensis defined at Kanam West, and we shall use this name.

Harris and White (1979) had noted that Ny. kanamensis differs from the earlier Ny. tulotos from Lothagam in its larger size, longer third molars, relatively smaller premolars, larger zygomatic inflation, and weaker supra-orbital ridges and supra-canine flange. In males, there is a distinct longitudinal supra-canine flange, and the lateral borders of the nasals also form slight longitudinal ridges that contribute to protect the muscles of the rostrum and their tendons, but both of these structures are much less clearly indicated than in Potamochoerus. The $\mathrm{P} 2$ and $\mathrm{p} 2$ are small, but the posterior premolars, especially $\mathrm{p} 3$ and p4, are quite large.

The specimens found by the early Patterson expeditions were described by Cooke and Ewer (1972), and some of those discovered more recently were illustrated by Harris et al. (2003); these authors provided the general characteristics of the species, but some specimens are worth a few more words. The features of the third molars and tooth proportions are discussed further down.

KP-18566 is a snout fragment with unerupted M3, interesting because P4 is unworn: this tooth is large and distinctly broader than M1, but otherwise differs little from that of other African suids. The metacone is smaller than the paracone and closely appressed against it, but these cusps are well distinct. There is no raised mesial and distal cingula, so that with wear the lingual and buccal parts of the tooth would have been separated by a longitudinal groove.

KP-30160 (Fig. 1H) is a partial, certainly female mandible that shows an i3 much smaller than the central incisors, a verrucose canine inserted rather vertically, and a minute $\mathrm{p} 2$ inserted against $\mathrm{p} 3$.

KP-30161 (Fig. 1D) is another partial, certainly male mandible in which the broken bone exposes the base of the large left canine, which certainly reached far behind p3.

KP-30177 consist of several pieces that confirm some of the characters listed above: on the little worn $\mathrm{P} 4$, the paracone and metacone are distinct but these cusps are separated from the protocone, $\mathrm{i} 3$ is much smaller than $\mathrm{i} 1$ and $\mathrm{i} 2$.

KP-30186 (Harris et al., 2003, fig. 17) is an almost complete male skull, but lacking most of the teeth. It is quite similar to KP-264, paratype of $N y$. 'pattersoni' (Cooke and Ewer, 1972, pl. 2C, 3) in its expanded, rounded zygomatic protuberances limited to the anterior part of the zygoma, depressed cranial roof bordered by strong lateral ridges in front of the orbits 
and sharply delimited from the temporal fossae by elevated crests, weak but distinct supracanine flanges, naso-maxillary suture forming a longitudinal ridge. In addition, it shows that the area immediately anterior to the orbit forms a depression that is less deep (especially dorsally) than in Potamochoerus, but much better expressed than in Hylochoerus. This depression is less clear in KP-264, but this area is less well preserved. It obviously served as an area of insertion of the rostral muscles (Ewer, 1958, 1970), confirming that these were intermediate between these two modern genera in their development.

KP-30205 and KP-30410 are the anterior parts of female mandibles, with short diastemas and small i3s.

KP-30267 is also the anterior part of a mandible but the size of its canine shows that it belongs to a male; the diastema is also short.

KP-30433 is a palate with moderately worn teeth, showing the incipient fusion of the buccal cusps of $\mathrm{P} 4$ with wear, and their clear separation from the protocone.

KP-38978 (Fig. 1G) is a partial mandible, probably male. The diastema is short. Although the $\mathrm{m} 3$ leaves no doubt as to species identification, the premolars are rather small.

KP-49362 is a maxilla with well-worn teeth; on P4 the paracone and metacone are fused, and separated by a groove from the protocone.

KP-50736 (Fig. 1E) is a mandibular symphysis with the base of the left canine and the roots of the premolars, which show that p3 and p4 must have been very large, thus definitely identifying the specimen as Ny. kanamensis. As in other specimens, the diastema is short, but the symphysis is also broad and dorso-ventrally flattened (perhaps accentuated by crushing).

KP-51146 (Fig. 1F) is an almost complete mandible that shows the same small i3 and short diastema as the previously mentioned female mandibles but differs in the larger size of the canine and is thus certainly male.

KP-56175 is an incomplete, juvenile, perhaps female cranium showing almost no zygomatic expansion, as in the female holotype of Ny. 'pattersoni' KP-239 (Cooke and Ewer, 1972, pl. 1); in contrast to males it shows no longitudinal supra-orbital ridges and no broadening of the skull roof at post-orbital level. We assume that these features result both from the gender and ontogenic age of the specimen.

KP-59955 is an associated set of upper teeth, including an M3. The protocone of P3 is relatively large. The two P4s display sub-equal paracone and metacone and, although the teeth are well-worn, these cusps are still separated by deep lingual and buccal clefts. 
= Nyanzachoerus plicatus Cooke and Ewer, 1972

As for the previous species, we add here a few words about the newly discovered specimens. Cooke and Ewer (1972) described the upper canines of the holotype KP-251, of KP-252, and of KP-262, but these are all female specimens. They correctly noted that they are directed less downwards than in the other species. By contrast, they assigned the large, male upper canines KP-242 and KP-267 (Cooke and Ewer, 1972, pl. 27A) to No. cf. capensis. KP57038 is an additional, almost complete similar large male upper canine; it is quite long, gently twisted, almost completely devoid of enamel, and has a rounded, slightly triangular cross-section. Because there is no definite evidence of No. capensis at Kanapoi, and because there is no other canine that could be attributed to No. jaegeri, we assign these teeth to the latter species; they much resemble those of Notochoerus euilus.

The upper premolars of the skull KP-30617 are poorly preserved, and those of KP211, which are definitely smaller than those of $N y$. kanamensis, are much worn, so that the only well-preserved P3 and P4 that definitely belong to No. jaegeri are those of the snout KP257 (Cooke and Ewer, 1972, pl.13D). They are not significantly smaller than those of Ny. kanamensis, and the only possible morphological difference is the seemingly smaller size of the lingual cusps; this could also be true of KP-30162, which is possibly also of No. jaegeri, but on the whole, no constant feature distinguishes the upper premolars of the two species. The ventral part of skull KP-30617 (Harris et al., 2003, fig. 19) is relatively well preserved. Compared to Ny. kanamensis (KP-264, KP-30186) the tooth-row is located distinctly more anteriorly and the snout looks both longer and broader, especially across the canines and premaxillae. The palate is also much longer behind M3s. The shape of the zygomatic expansions is unknown because the arches are very incomplete, but in ventral view they emerge much less transversally than in $N y$. kanamensis, and definitely more like in No. euilus. The occipital is not broad, but it looks so because the deep notch that separates, in Ny. kanamensis, and still more so in Ny. tulotos (e.g., LT-23771), the occipital from the posterior part of the zygoma and auditory canal is here filled by a bony plate increasing the areas of insertions of both the temporalis and nuchal muscles. In this regard, KP-30617 resembles No. euilus.

No significant mandibular remain has been discovered recently. We had previously explained (Geraads et al., 2013) why the mandible KP-30184 can satisfactorily be included in No. jaegeri rather than in No. cf. euilus, as was done by Harris et al. (2003). Cooke and Ewer (1972) also had assigned a number of specimens to No. cf. capensis or No. cf. euilus, but these were transferred to No. jaegeri by Harris et al. (2003). 


\subsection{Nyanzachoerus $c f$. tulotos Cooke and Ewer, 1972}

The only specimen from the Kanapoi beds that cannot be placed in either Ny. kanamensis or No. jaegeri is EK-270, which consists of associated P4, incomplete M1, and M3 (Fig. 1I). It comes from Ekora but below the Kalokwanya basalt, so that its age is greater than 3.4 Ma, but presumably younger than the main Kanapoi fauna. It was briefly described by Cooke and Ewer (1972) who assigned it to Nyanzachoerus cf. pattersoni (recte: Ny. kanamensis) but, compared to this species, $\mathrm{P} 4(17.8 \times 25.3 \mathrm{~mm})$ is broader relative its length, and broad relative to M3; in addition, M3 (41.8 x $28.7 \mathrm{~mm})$ is very brachyodont, and much shorter, thus relatively much broader relative to its length. This M3 is also relatively much broader than those of Kolpochoerus ( see e.g., Cooke, 1976, fig. 3), and much larger than Kolpochoerus of this age. These tooth dimensions and proportions compare favorably with those of Ny. tulotos from Lothagam and Nkondo (NK 50'88 is virtually identical in dimensions and morphology: Pickford, 1994, pl.3, fig.9), but the pattern of P4 looks distinct: in Ny. tulotos, the buccal cusps make up most of the crown (fig. 5 of Harris and White, 1979, is incorrect in this regard; compare Cooke and Ewer, 1972, pl.24A), and they are clearly separated from the lingual cusp complex by a deep longitudinal groove, whereas in EK-270 they are less dominant on the crown surface, more like in others species of Nyanzachoerus. Harris and White (1979:19) believed EK-270 was intermediate between Ny. tulotos and Ny. kanamensis. A few specimens from the Apak Mb of Lothagam have also been described as $N y$. tulotos (Harris and Leakey, 2003) but from their dimensions they are less clearly distinct from Ny. kanamensis and match better this species. EK-270 is too incomplete for formal identification, but it is certainly close to $N y$. tulotos, suggesting either a late survival of this species at Ekora or the occurrence of beds of earlier age in this region, or reworking of some fossils.

\section{Discussion}

3.1. Distinction of Ny. kanamensis and No. jaegeri and evolution of Pliocene Nyanzachoerus An excellent introduction to the taxonomic history of African Pliocene suids of the Nyanzachoerus-Notochoerus group has been provided by Haile-Selassie (2009), and there is no need to repeat it here (see also Bishop, 2010, for an overview of the systematics of African suids). The pioneering publication of Leakey (1958) was not followed by a modern revision until White and Harris (1977, Harris and White, 1979), in parallel with Cooke and colleagues (Cooke and Ewer, 1972; Cooke, 1978; Cooke and Wilkinson, 1978) elaborated the first draft 
of the evolution of this group. Pliocene Nyanzachoerus is supposed to be derived from 'Propotamochoerus' devauxi Arambourg, 1968 from the early late Miocene of Algeria. Several species of the genus have been named, although no agreement has been reached as to their definition. As in several other African suid lineages, it is assumed that their third molars increased in length and complexity through time. Coppens (1971) described from Hamada Damous in Tunisia, a site whose age is poorly constrained, a derived form with lengthened third molars that he called Ny. jaegeri. Because of this derived character and the shape of its mandibular symphysis, Harris et al. (2003) regarded it as representing an early form of the genus Notochoerus, contributing to fill the gap between those genera. This generic assignment has generally been accepted since then, but Gebreyesus (2011) questioned it on the basis of cranial characters. Obviously, the distinction or transition between those genera remains one of the key issues regarding Pliocene African suids.

According to Harris et al. (2003), one of the main distinguishing features of No. jaegeri, by comparison with Ny. kanamensis is the spatulate shape of the mandibular symphysis, which is broad, with relatively flat dorsal and ventral surfaces, and with the incisors arranged in a transverse line rather than along an arch (Fig. 1). These differences are probably true as a whole, but they are hard to appreciate because of the frequent transverse crushing of the mandibles, and imperfect preservation of the incisive alveolar border; in addition KP-50736 that is definitely of Ny. kanamensis also has a broad, spatulate symphysis (Fig. 1E). In fact, by far the best distinguishing feature in the mandible is the length of the post canine diastema (Table 1), which shows no overlap between both species, both sexes combined; the correlated symphysis length also shows no overlap when sexes are distinguished. That the role of this longer diastema in No. jaegeri is not just to accommodate a longer canine root is shown by KP-30161 (Fig. 1D), a mandible of Ny. kanamensis in which the canine reaches at least the back of $\mathrm{p} 4$. This lengthening of the anterior portion of the mandible obviously correlates with a lengthened snout, as suggested by the type of 'Ny. plicatus', but too few specimens are preserved to demonstrate this.

In almost all mandibles of $N y$. kanamensis where this area is preserved, a small p2 is present, closely appressed against p3; in rare instances it may be absent of monoradiculated. By contrast, this tooth is normally either absent or separated from $\mathrm{p} 3$ by a diastema in the Kanapoi No. jaegeri (although this is not true of the type specimen from Hamada Damous). Upper and lower posterior premolars of No. jaegeri are smaller than those of Ny. kanamensis, but their size ranges widely overlap (Fig. 2); the L/W plots of these teeth show no bimodality, and only the largest teeth can be definitely identified as $N y$. kanamensis. 
Cooke and Ewer (1972) stated that $N y$. 'pattersoni' is brachyodont, whereas 'Ny. plicatus' would be 'slightly hypsodont'. In fact, the difference in hypsodonty is at most slight. Unworn m3s of $N y$. kanamensis (KP-30409, KP-30620) are slightly taller than broad; there is no unworn $\mathrm{m} 3$ of No. jaegeri, but slightly worn ones suggest that the difference between height and width was not much larger.

The third lower molars of $N y$. kanamensis have three pairs of pillars, plus a small talonid; it may consist of more than a single tubercle, but they are never paired. Those of No. jaegeri always have at least an incipient fourth pair; it may be followed by one or more accessory posterior cuspid(s), but they may also be fully absent (KP-30180). Thus, the difference between the two species in talonid development behind the third pair may be slight, but the criterion of incipient fourth pair works perfectly. It is clear, however, that this difference in talonid development fails to fully explain the difference in length of the $\mathrm{m} 3 \mathrm{~s}$, which is achieved by a lengthening of each individual pair of pillars; indeed, in teeth assigned to Ny. kanamensis, the pillars are mushroom-shaped, whereas in those of No. jaegeri, they assume the shape of an horizontal H (i.e., with deeper anterior and posterior groves). In addition, in upper M3s of $N y$. kanamensis, the metacone and hypocone (second pair of pillars) come in full contact in the midline of the tooth, whereas in those of No. jaegeri (KP-234, KP253 [Cooke and Ewer, 1972, pl.17G-H], KP-257 [figure 11 of Harris and White, 1979, is incorrect in this regard - see instead Cooke and Ewer, 1972, pl.16], KP-30617, KP-49367) central accessory pillars intervene between them. This difference is sometimes hard to appreciate because of the irregular shape of the pillars and changes with wear, but there is no doubt that it is true on the whole. This lack of contact is common in Metridiochoerus, as noted by Pickford (2013); by contrast, in almost all other specimens of Nyanzachoerus that we have seen, including several specimens of No. jaegeri from the Omo, the metacone and hypocone come into contact in the midline, and this is also true of the type specimen (Coppens, 1971, pl.2). In No. euilus, the contact may be present or not (compare Harris and White, 1979, figs 29 and 31). Thus, we believe that not too much weight should be placed upon this character (contra Pickford, 2013 - see also suppl. info.), not only because it is sometimes hard to appreciate, but also because it varies between closely related species, if not within species.

A graph of the measurements of a large number of Pliocene and early Pleistocene East African Nyanzachoerus and Notochoerus is presented in Fig. 3 and SI. Harris et al. (2003) stated that male 'teeth' (third molars being probably meant) of $N y$. kanamensis are larger than those of females, but the available sample of specimens that can definitely be sexed does not confirm this assertion, and there is no evidence that Nyanzachoerus differs in this regard from 
modern Sus, where sexual dimorphism in molar dimensions is virtually absent (Van der Made, 1991). Lower teeth have been chosen in preference to upper ones because both isolated teeth and associated sets of molars and premolars are more numerous. They illustrate the main features commonly assumed to characterize species of this group: the lengthening of the third molars (Lm3 x Wm3, Fig. 3), and the relative width of the premolars (Lm3 x Wp3 and Lm3 x Wp4, SI Figs 1-2).

The first obvious result is that, although we sampled a large time interval (from the late Miocene to the early Pleistocene), two main clouds can be distinguished, with few intermediate forms, although some marginal specimens plot outside the main clouds. The left cloud (with short m3s) includes teeth assigned to typical Nyanzachoerus. The sample from the Lower Nawata Mb of Lothagam, assigned to $N y$. tulotos, has short but relatively broad m3s. Most of the remaining specimens have homogeneous L / W proportions, and belong to Ny. kanamensis: the type and paratype of Leakey, 1958, from Kanam West, the large sample from the Hadar Formation, the Kanapoi sample, some specimens from the Turkana Basin and Galili, and those from Manonga (Bishop, 1997). This cloud also includes the latest Miocene material of the Middle Awash that Haile-Selassie (2009) called Ny. australis but that can, in our opinion, be included in Ny. kanamensis; the distal part of $\mathrm{m} 3$ does not differ in this regard (Boisserie et al., 2014). All these populations are quite similar to each other, the $\mathrm{m} 3 \mathrm{~s}$ from the Hadar Formation being only slightly longer than those from the earlier sites. Besides this slight difference in $\mathrm{m} 3$ length, the relative proportions of the premolars are also similar, showing that this species underwent little evolutionary change with time. The Lothagam teeth are slightly shorter, and the Nkondo ones are clearly smaller, warranting distinction as Ny. waylandi (Pickford, 1989, 2014). The holotype of Ny. kuseralensis Haile-Selassie, 2009 from the Kuseralee $\mathrm{Mb}$ of the Middle Awash is of similar size but is more primitive in lacking a third pair of pillars, whereas all five m3s of $N y$. waylandi from Uganda seen by us have a well-formed third pair; thus, the conclusion of Boisserie et al. (2014) that both names are synonymous is perhaps hasty.

The right cloud includes specimens assigned to No. jaegeri and other Notochoerus. The former taxon can be distinguished by its relatively broader teeth (both the width of $\mathrm{p} 3$ and that of $\mathrm{m} 3$ are smaller relative to $\mathrm{m} 3$ length), while the teeth of Notochoerus become increasingly narrow with time. Delimitation of species within this large cloud is obviously difficult. Even in a single site such as Kanapoi, the size range is large, and choosing a specimen at both ends of it might suggest the occurrence of two distinct species, such as was done by identifying No. euilus at this site. On the basis of tooth morphology, No. euilus can 
easily be descended from No. jaegeri, and the long snout with a straight dorsal profile of the holotype of $N y$. plicatus (Cooke and Ewer, pl.13A-B), and the zygomatic bony knob KP-242 (Cooke and Ewer, pl.27C-D) definitely resemble Notochoerus.

Another issue is the possible origin of No. jaegeri from Ny. kanamensis or from some other Nyanzachoerus with short molars. It is interesting to observe that while there are some outliers, there is clearly no continuum between the two main clouds, and the regression lines of Ny. kanamensis and No. jaegeri at Kanapoi (and other sites) are clearly distinct, so that a gradual, direct evolution of $N y$. kanamensis into No. jaegeri can probably be rejected. The only intermediate forms are the group of large size from Nkondo (group 2 of Pickford, 1994). Pickford (1994) called it Ny. jaegeri but the very large premolars rule out this identification; this group 2 looks more like an enlarged version of $N y$. kanamensis, although there is an incipient fourth pair of cuspids on m3, almost matching that of No. jaegeri. Because the premolars decreased in size and the molars became narrower from No. jaegeri to No. euilus (if these species are really a lineage), it is conceivable that No. jaegeri arose from such a form, although group 2 shows no trend in this direction. The Woranso-Mille skull described by Gebreyesus (2011) as Ny. jaegeri is very different from that of Notochoerus, and it is indeed hard to believe that the species it represents is ancestral to this genus, but it may also be that this skull is in fact a derived version of a kanamensis-like form: the ante-premolar portion is quite short, the choanae located not far behind M3, the tooth row is located anteriorly, and P4 is large (as at Nkondo). All these features are very different from those of KP-30617, and similar to Nyanzachoerus s. str.

\subsection{Ecology of Nyanzachoerus at Kanapoi}

Because of their large size and of abundance, Nyanzachoerus and Notochoerus certainly played a greater role in the Kanapoi ecosystem than modern suids in present-day Africa. Their only possible predators were the saber-toothed felid Homotherium, and perhaps the leopard-size Dinofelis petteri. We can imagine that they were able to thrive in the open, without the need to hide from these carnivores, especially if they lived in relatively large groups. The large size of the zygomatic bony expansions, whose display certainly played a role in agonistic behavior, also suggest life outside dense vegetation.

Cooke and Ewer (1972:214) and Cooke (1985) attempted some dietary interpretations from the cranial functional anatomy of Nyanzachoerus. One may hypothesize that the enlarged premolars were used to process tough food, and that they were no longer needed in Notochoerus when its diet changed, also involving lengthening of the third molars and 
perhaps slightly increased hypsodonty. It is noticeable, however, than most premolars of Ny. kanamensis are little worn, and that they seem to start being in full use only after the $\mathrm{m} 1 \mathrm{~s}$ and $\mathrm{m} 2 \mathrm{~s}$ are worn out. These authors also observed that the broad mandibular symphysis, the moderately developed rostral muscles, and the relative proportions of the temporalis and masseter muscles, are intermediate between Potamochoerus and Phacochoerus, suggesting less rooting than in the former genus, but less grazing than in the latter.

Fig. 4 shows the $\delta{ }^{13} \mathrm{C}$ values of tooth enamel of suids of the Nyanzachoerus Notochoerus group. Using the identifications provided by the authors we distinguished those with short third molars (Ny. kanamensis, $N y$. tulotos-syrticus-australis) from those with long ones (No. jaegeri and other Notochoerus), but this distinction is impossible for many specimens, as isotope analyses are, regrettably, often conducted on fragments. In addition, it is likely that many of the identifications are not reliable, given the similarities between the various taxa. Given these reservations, the first obvious conclusion, in agreement with the observations of Harris and Cerling (2002), is that very few of them were pure browsers, and that there is a general trend towards incorporation of more $\mathrm{C} 4$ grasses in the diet. It is also clear that, on the whole, suids with long third molars were more grazers than those with short ones, but the correlation is far from perfect, as there are Ny. kanamensis that were grazers, and some Notochoerus that were not. At Kanapoi, both grazers and mixed feeders co-exist, but the material is too incomplete for species identification. Given the large overlap of isotopic values in other sites of the $4.5-3$ Ma time-range, it is likely that the diets of these species also overlapped at Kanapoi, as also suggested by the similarities of their dentitions.

One of the most significant features of the Kanapoi suid assemblage is the absence of Kolpochoerus, which we regard as significant, given the large number of collected specimens. According to Brunet and White (2001), this genus makes its first appearance in the region at c. 4.4 Ma in the Middle Awash, but they also described older material from Kossom Bougoudi in Chad, and Pickford (2012) described (as Dasychoerus) a similar form from Wadi Natrun in Egypt. Still, the genus remains absent from many early Pliocene East African sites, including Galili (Kullmer et al., 2008) and the whole Turkana basin below the Tulu Bor tuff. This certainly lends support to the hypothesis of Pickford (2012) that the genus is of northern origin and derives from (or is identical with) the Eurasian Dasychoerus. We can imagine that in the early Pliocene of Ethiopia and Uganda these early Kolpochoerus were unable to compete with small Nyanzachoerus ( $N y$. waylandi, Ny. kuseralensis), and that it is only with the disappearance of these small species (extinction or evolution into larger forms) that 
Kolpochoerus became so successful. However, this tentative interpretation does not hold for the Turkana Basin, where no small Nyanzachoerus is known.

During the whole Pliocene, No. jaegeri and No. euilus progressively replaced Nyanzachoerus (Table 2). The first representatives of Notochoerus appear at Nkondo (assuming that the date of $5 \mathrm{Ma}$ is correct) and perhaps Aramis and Kollé (but this material still has to be published). The shift in relative abundance mainly takes place between c. 4 and 3.3 Ma. It may have to do with climate change but is very progressive throughout the Pliocene.

\section{Conclusions}

The current collection of Pliocene Kanapoi Suidae consists of at least 120 distinct specimens (individuals), most of these identified as Nyanzachoerus kanamensis, and the remaining ones as Notochoerus jaegeri. These two species are closely related, and may constitute an ancestordescendant evolutionary relationship, although establishing the exact nature of this transition remains a key problem in African Pliocene suid evolution. Thus, the Kanapoi fauna samples only one of the subfamilies (and one tribe) of suids: the Tetraconodontinae. Contemporaneous suids present elsewhere in Africa, most notably Kolpochoerus, remain absent from the collection, probably for biogeographical reasons (rather than insufficient sampling). Suids along with other mammals play a prominent role in environmental and ecological reconstructions of Pliocene African sites. The stable isotopic signature of Kanapoi suids indicates that both Nyanzachoerus kanamensis and Notochoerus jaegeri were mixed feeders (following the dietary classification of Cerling et al. 2015), suggesting that the habitats shared by these species with early Australopithecus were mosaics of grassy and woody vegetation. These data are included in a broader paleoecological discussion of Kanapoi elsewhere in this volume.

\section{Acknowledgements}

We are grateful to C. Ward, F.K. Manthi, and M. Plavcan for having invited us to participate in this special issue about Kanapoi, and to all people who allowed access to

modern and fossil collections: C. Argot and J. Lesur (MNHN), P. Brewer and A. Currant (NHMUK), M. Muungu (KNM), and G. Senichaw (NME). Many thanks also to M. Pickford (MNHN) for generously sharing his collection of casts. Recent field work at Kanapoi was supported by NSF grants BCS-1231749 (to C. Ward and F.K. Manthi), BCS-1231675 (to 
M. Plavcan and P. Ungar), the Wenner Gren Foundation, and the University of Missouri Research Board.

\section{References}

Arambourg, C., 1948. Contribution à l'étude géologique et paléontologique du bassin du lac Rodolphe et de la basse vallée de l'Omo. Deuxième partie: Paléontologie. Mission Scientifique de l'Omo 1932-1933. Tome I. Fasc. 3: Géologie - Anthropologie. Éditions du Muséum, Paris, pp. 231-562.

Arambourg, C., 1968. Un suidé fossile nouveau du Miocène supérieur de l'Afrique du Nord. Bull. Soc. Géol. Fr. 7, 110-115.

Bishop, L.C., 1997. Fossil suids from the Manonga Valley, Tanzania. In: Harrison, T. (Ed.), Neogene Paleontology of the Manonga Valley, Tanzania. Plenum Press, New York, pp. 191-217.

Bishop, L.C., 2010. 42. Suoidea. In: Werdelin, L., Sanders, W.J. (Eds.), Cenozoic Mammals of Africa, University of California Press, Berkeley, pp. 821-842.

Bishop, L.C., 2011. Chapter 13. Suidae. In: Harrison, T. (Ed.), Paleontology and Geology of Laetoli: Human Evolution in Context. Vol. 2: Fossil Hominins and the associated fauna. Springer, Dordrecht, pp. 327-337.

Boisserie, J.-R., Souron, A., Mackaye, H.T., Likius, A., Vignaud, P., Brunet, M., 2014. A New Species of Nyanzachoerus (Cetartiodactyla: Suidae) from the Late Miocene Toros-Ménalla, Chad, Central Africa. PLoS ONE 9(8): e103221. doi:10.1371/journal.pone.0103221

Brunet, M., White, T.D., 2001. Deux nouvelles espèces de Suini (Mammalia, Suidae) du continent africain (Éthiopie ; Tchad). C. R. Acad. Sci. Paris 332, 51-57.

Cerling, T.E., Andanje, S.A., Blumenthal, S.A., Brown, F.H., Chritz, K.L., Harris, J.M., Hart, J.A., Kirera, F.M., Kaleme, P., Leakey, L.N., Leakey, M.G., Levin, N.E., Manthi, F.K., Passey, B.H., Uno, K.T., 2015. Dietary changes of large herbivores in the Turkana Basin, Kenya from 4 to 1 Ma. Proc. Natl. Acad. Sci. doi/10.1073/pnas.1513075112

Cooke, H.B.S., 1976. Suidae from Plio-Pleistocene strata of the Rudolf basin. In: Coppens, Y., Howell, F.C., Isaac, G.Ll., Leakey, R.E.F. (Eds.), Earliest man and environments in the Lake Rudolf Basin. University of Chicago Press, Chicago., pp. 251-263.

Cooke, H.B.S., 1978. Suid evolution and correlation of African hominid localities: an alternative taxonomy. Science 201: 460-463. 
Cooke, H.B.S., 1985. Plio-Pleistocene Suidae in relation to African hominid deposits. In: L'environnement des Hominidés au Plio-Pléistocène. Masson, Paris. pp. 101-117. Cooke, H.B.S., Wilkinson, A.F., 1978. Suidae and Tayassuidae. In: Maglio, V.J., Cooke, H.B.S. (Eds.), Evolution of African Mammals. Harvard University Press, Cambridge, pp. $435-482$.

Cooke, H.B.S., Ewer, R.F., 1972. Fossil Suidae from Kanapoi and Lothagam, Northwestern Kenya. Bull. Mus. Comp. Zool. 143, 149-296.

Coppens, Y., 1971. Une nouvelle espèce de suidé du Villafranchien de Tunisie, Nyanzachoerus jaegeri nov. sp. C. R. Acad. Sci., Paris 272, 3264-3267.

Drapeau, M., Bobe, R., Wynn, J., Campisano, C., Dumouchel, L., Geraads, D., 2014. The Omo Mursi Formation: a window into the East African Pliocene. J. Hum. Evol. 75, 64-79.

Ewer, R.F., 1958. Adaptive features in the skulls of African Suidae. Proc. Zool. Soc. London $131,135-155$.

Ewer, R.F., 1970. The head of the forest hog, Hylochoerus meinertzhageni. E. Afr. Wildl. J. 8, $43-52$.

Fara, E., Likius, A., Mackaye, H.T., Vignaud, P., Brunet, M., 2005. Pliocene large-mammal assemblages from northern Chad: sampling and ecological structure. Naturwissenschaften 92, 537-541.

Fessaha, N., 1999. Systematics of Hadar (Afar, Ethiopia) Suidae. Ph.D. thesis, Howard University.

Gebreyesus, H., 2011. The origin and evolution of Notochoerus euilus (Suidae): fossil evidence from Woranso-Mille, Central Afar, Ethiopia. Unpubl. thesis, Univ. of Addis Ababa.

Geraads, D., Bobe, R., Manthi, F.K., 2013. New ruminants (Mammalia) from the Pliocene of Kanapoi, Kenya, and a revision of previous collections, with a note on the Suidae. J. Afr. Earth Sci. 85, 53-61.

Haile-Selassie, Y., 2009. 10. Suidae. In: Haile-Selassie, Y., WoldeGabriel, G. (Eds.), Ardipithecus kadabba, Late Miocene evidence from the Middle Awash, Ethiopia. University of California Press, Berkeley, pp. 331-371.

Harris, J.M., 1983. Family Suidae. In: Harris, J.M. (Ed.), Koobi Fora Research Project, Volume 2: The Fossil Ungulates: Proboscidea, Perissodactyla and Suidae. Clarendon Press, Oxford, pp. 215-302. 
Harris, J.M., Cerling, T.E., 2002. Dietary adaptations of extant and Neogene African suids. J. Zool. 256, 45-54.

Harris, J.M., Leakey, M.G., 2003. Lothagam Suidae. In: Leakey, M.G., Harris, J.M. (Eds.), Lothagam - The Dawn of Humanity in Eastern Africa. Columbia University Press, New York, pp. 485-519.

Harris, J.M., White, T.D., 1979. Evolution of the Plio-Pleistocene African Suidae. Trans. Amer.Phil. Soc. 69, 1-128.

Harris, J.M., Leakey, M.G., Cerling, T.E., Winkler, A.J., 2003. Early Pliocene tetrapod remains from Kanapoi, Lake Turkana Basin, Kenya. In: Harris, J.M., Leakey, M.G. (Eds.), Geology and Vertebrate Paleontology of the Early Pliocene site of Kanapoi, Northern Kenya (Contributions in Science 498). Natural History Museum of Los Angeles County, Los Angeles, pp. 39-113.

Kingston, J.D., 2011. Chapter 15. Stable isotopic analyses of Laetoli fossil herbivores. In: Harrison, T. (Ed.), Paleontology and Geology of Laetoli: Human Evolution in Context. Vol. 2: Fossil Hominins and the associated fauna. Springer, Dordrecht, pp. 275-294. Kullmer, O., Sandrock, O., Bence Viola, T., Hujer, W., Said, H., Seidler, H., 2008. Suids, elephantoids, paleochronology, and paleoecology of the Pliocene hominid site Galili, Somali Region, Ethiopia. Palaios 23, 452-464.

Leakey, L.S.B., 1958. Some East African Pleistocene Suidae. Fossil Mammals of Africa 14. $1-132$.

Orliac, M.J., Antoine P.-O., Ducrocq, S. 2010. Phylogenetic relationships of the Suidae (Mammalia, Cetartiodactyla): new insights on the relationships within Suoidea. Zool. Scripta 39, 315-330.

Pickford, M., 1989. New specimens of Nyanzachoerus waylandi (Mammalia, Suidae, Tetraconodontinae) from the type area, Nyaburogo, (Upper Miocene), Lake Albert rift, Uganda. Geobios 22, 641-651.

Pickford, M., 1994. Fossil Suidae of the Albertine Rift, Uganda-Zaïre. In: Senut, B., Pickford, M., (Eds.), Geology and Palaeobiology of the Albertine Rift Valley, Uganda-Zaïre II : Palaeobiology. Cifeg. Orléans, pp. 339-373.

Pickford, M., 2012. Ancestors of Broom's pigs. Trans. R. Soc. S. Afr. 67, 17-35.

Pickford, M., 2013. Reappraisal of Hylochoerus euilus Hopwood, 1926 (Suidae, Mammalia) from the Albertine Rift (Pliocene) Uganda. Geo-Pal Uganda 6, 1-26. 
Pickford, M., 2014. Sus valentini Filhol, 1882 from St Gaudens (MN 8-9) France: blighted from the outset but a key to understanding late Middle Miocene Tetraconodontinae (Suidae, Mammalia) of Europe. Mainzer naturwiss. Archiv 51, 167-220.

Uno, K.T., Cerling, T.E., Harris, J.M., Kunimatsu, Y., Leakey, M.G., Nakatsukasa, M., Nakaya, H., 2011. Late Miocene to Pliocene carbon isotope record of differential diet change among east African herbivores. Proc. Natl. Acad. Sci. USA 108, 6509-6514.

Van der Made, J., 1991. Sexual bimodality in some recent pig populations and application of the findings to the study of fossils. Z. Säugetierk. 56, 81-87.

Van der Made, J., 1999. Biometrical trends in the Tetraconodontinae, a subfamily of pigs. Trans. R. Soc. Edinburgh, Earth Sci. 89, 199-225.

White, T.D., Harris, J.M., 1977. Suid evolution and correlation of African hominid localities. Science 198, 13-21.

White, T., Suwa, G., 2004. A new species of Notochoerus (Artiodactyla, Suidae) from the Pliocene of Ethiopia. J. Vert. Paleontol. 24, 474-480.

White, T.D., Ambrose, S.H., Suwa, G., Su, D.F., DeGusta, D., Bernor, R.L., Boisserie, J.-R., Brunet, M., Delson, E., Frost, S., Garcia, N., Giaourtsakis, I.X., Haile-Selassie, Y., Howell, F.C., Lehmann, T., Likius, A., Pehlevan, C., Saegusa, H., Semprebon, G., Teaford, M., Vrba, E., 2009. Macrovertebrate paleontology and the Pliocene habitat of Ardipithecus ramidus. Science 326, 87-93.

Zazzo, A., Bocherens, H., Brunet, M., Beauvilain, A., Billiou, D., Mackaye, H.T., Vignaud, P., Mariotti, A., 2000. Herbivore paleodiet and paleoenvironmental changes in Chad during the Pliocene using stable isotope ratios of tooth enamel carbonate. Paleobiology 26, 294-309.

\section{Captions to figures}

Fig. 1. A-H: some of the most complete suid mandibles from Kanapoi; A-B: Notochoerus jaegeri; C-H: Nyanzachoerus kanamensis. A: KP-30178, male; B: KP-30452, male; C: KP239, female; D: KP-30161, male; E: KP-50736, male; F: KP-51146, male; G: KP-38978, male ?. H: KP-30160, female. I: Nyanzachoerus cf. tulotos, left M3 EK-270 in mesial and occlusal views. Scale $=20 \mathrm{~cm}$ for Figs A-H, $5 \mathrm{~cm}$ for Fig. I. 
Fig. 2. Plot of length vs. width of p3 and p4 of Ny. kanamensis and No. jaegeri from Kanapoi. Teeth identified to species are those that are associated with m3s.

Fig. 3. Scatterplot of length vs. width of $\mathrm{m} 3 \mathrm{~s}$ in various samples of species assigned to Nyanzachoerus and Notochoerus. Most measurements are our own, except for Galili (Kullmer et al., 2008), Nkondo (Pickford, 1994, with some corrections), Wormil (Gebreyesus, 2011), and a few measurements from Harris (1983), White and Suwa (2004), and Fessaha (1999). In addition, for the Omo Shungura Fm, we added measurements digitized from graphs in Cooke (1976). Cooke did not mention how he took his measurements, so that they may be slightly over-estimated, but this is unlikely to significantly alter the comparisons. Some regression lines (reduced major axis) are also indicated.

Fig. 4. $\delta{ }^{13} \mathrm{C}$ values of dental enamel of Central and Eastern African fossil Suidae of the Nyanzachoerus - Notochoerus group. Data (see SI Table 1) from Bedaso et al. (2013), Boisserie et al. (2014), Cerling et al. (2015), Drapeau et al. (2014), Harris et al. (2003), Kingston (2011), Levin et al. (2008), Uno et al. (2011), White et al. (2009), Zazzo et al. (2000). 